\title{
Correction to: Application of Nanomaterials in the Diagnosis and Treatment of Genetic Disorders
}

\author{
Alaa A. Aljabali, Mohammad A. Obeid, Haneen A. Amawi, \\ Meriem M. Rezigue, Yassmen Hamzat, Saurabh Satija, \\ and Murtaza M. Tambuwala
}

\section{Correction to:}

Chapter 7 in: F. A. Khan (ed.), Applications of Nanomaterials in Human Health, https://doi.org/10.1007/978-981-15-4802-4_7

The original version of the book was inadvertently published with a spelling error in an author's surname in Chapter 7. The author's (7th author) name has now been corrected as "Murtaza M. Tambuwala".

M. M. Tambuwala

School of Pharmacy and Pharmaceutical Science, SAAD Centre for Pharmacy and Diabetes, Ulster University, Coleraine, UK

The updated online version of this chapter can be found at https://doi.org/10.1007/978-981-15-4802-4_7 